\title{
Ultrastructural and Physiological Characterization of YELP, a Novel, Yellow, Chlorophyll-Deficient Cell Mutant Line That Develops Etioplast-Like Plastids in the Light
}

\author{
Betzaida Jiménez-Francisco1, Carlos Trejo', Hilda Araceli Zavaleta-Mancera1, \\ Blanca Moreno-Gómez², Edmundo García-Moya1, Florentino Víctor Conde-Martínez', \\ Gerardo Armando Aguado-Santacruz ${ }^{3 *}$ \\ ${ }^{1}$ Potgrado en Botánica, Colegio de Postgraduados, Texcoco, México \\ ${ }^{2}$ Campo Experimental Bajío, Instituto Nacional de Investigaciones Forestales y Agropecuarias, Celaya, México \\ ${ }^{3}$ Programa de Posgrado, Instituto Tecnológico de Roque, Celaya, México \\ Email: jimenez.betzaida@colpos.mx, catre@colpos.mx, arazavaleta@colpos.mx, \\ blancam1980@yahoo.com.mx,edmundo@colpos.mx,vconde@colpos.mx, "gaguado@prodigy.net.mx
}

Received 22 January 2016; accepted 20 March 2016; published 23 March 2016

Copyright @ 2016 by authors and Scientific Research Publishing Inc.

This work is licensed under the Creative Commons Attribution International License (CC BY).

http://creativecommons.org/licenses/by/4.0/

(c) (i) Open Access

\begin{abstract}
In this work, we present an ultrastructural and physiological description of a novel chlorophylldeficient, yellow cell line of the grass Bouteloua gracilis that develops etioplast-like plastids in presence of light (YELP). These mutant cells were compared to the parental, wild-type, highly chlorophyllous cells from which they were isolated. Growth analysis, based on fresh and dry weights, indicated that YELP accumulates biomass at a slower rate than the parental, green cells. Besides, YELP developed very low levels of photosynthetic pigments, reaching only $9.3 \%$ and $38.4 \%$ of chlorophyll a and chlorophyll $b$, respectively, developed by the wild-type cells. Likewise, the accessory pigments, carotenes and xanthophylls, were only synthesized at $8.0 \%$ and $5.4 \%$, respectively, of the levels reached by the green cells. Electron microscopy revealed remarkable differences in plastid ultrastructure between the wild-type and mutant cells. Plastids of YELP were heterogeneous and smaller than those found in wild-type cells. YELP plastids were abnormal with poorly developed membrane systems that prevented the accumulation of chlorophyll and accessory pigments in the mutant cell line. We expect this novel, mutant cell line will provide new tools for studying plastid development and differentiation.
\end{abstract}

${ }^{*}$ Corresponding author.

How to cite this paper: Jiménez-Francisco, B., et al. (2016) Ultrastructural and Physiological Characterization of YELP, a Novel, Yellow, Chlorophyll-Deficient Cell Mutant Line That Develops Etioplast-Like Plastids in the Light. American Journal of Plant Sciences, 7, 510-524. http://dx.doi.org/10.4236/ajps.2016.73045 


\section{Keywords}

\section{Cell Suspension, Chloroplast Biogenesis, Prolamellar Body, Ultrastructure}

\section{Introduction}

Chlorophyll is the dominant pigment in nature and one of the most abundant organic molecules on earth. Chlorophyll is involved in the absorption and transfer of energy in the process of photosynthesis. Chlorophyll deficiency in photosynthetic organisms, such as cyanobacteria, algae and plants, is a common consequence of nuclear or plastomic mutations that occur spontaneously or can be artificially induced by chemical or physical agents [1]. These mutations are primarily identified by abnormal pigmentation patterns in the organisms carrying these genetic alterations and can be classified into two main groups. The first group comprises homogeneous, unicolor mutants, while the second one includes heterogeneous multicolor mutants. Mutants such as albino, viridis and xantha are included in the first group, while zonata, alboviridis, xanthalba, virido-albino, tigrina, striata, maculata and alboxantha are examples of multicolor mutants [2].

The origins of the mutations causing chlorophyll deficiency are highly diverse but include alterations in genes related to the biosynthetic pathways of photosynthetic pigments (chlorophylls and carotenoids), disturbances in lipid metabolism and the synthesis of proteins integrating the photosynthetic membranes [3], deficiencies in protein transport into the chloroplast [4], and alterations in chloroplast biogenesis and differentiation [5]. Additionally, mutations in mitochondria are also conducive to altered chlorophyll accumulation patterns and function. Differentiating mutants affected in chlorophyll biosynthesis from those impaired in other pathways, such as carotenoid biosynthesis, is complicated because the routes for chlorophyll and carotenoid biosynthesis, as well as those related to chloroplast biogenesis, are interrelated. Thus, mutants that are unable to develop normal profiles of carotenoids can also be affected in their chlorophyll accumulation due to the instability of this pigment in the absence of the carotenoid complement and because these failures are conducive, in turn, to developmental arrest of the chloroplast [6]. On the other hand, chlorophyll accumulation abnormalities can also be caused by malfunctioning of other organelles. For example, disruption of mitochondrial function affects chloroplast development and results in a phenotype characterized by irregular chlorophyll accumulation [7].

The phenotypic expression of some mutants is markedly affected by the manipulation of environmental factors, such as light [8] and temperature [9], while certain mutations related to chlorophyll biosynthesis can be reversed by the addition of exogenous compounds or precursors, such as the ferrous ion, amino acids, thiamine or sugars [10].

In spite of these difficulties to characterize mutants with atypical production of photosynthetic pigments due to pleiotropic effects, physiological, biochemical and molecular studies have identified different genes associated with the synthesis of chlorophyll and chloroplast development. The OsCHLH gene encodes the largest subunit of the rice Mg-chelatase, a key enzyme crucial for the conversion of protoporphyrin-IX (ProtoIX) into Mg-protoporphyrin-IX within the chlorophyll biosynthetic pathway [11]. The mutation of this gene in Chlamydomonas reinhardtii results in the accumulation of protoporphyrin-IX, and the organisms show yellow or orange pigmentation due to disrupted chlorophyll synthesis [12]. Cloning of the chlorophyll aoxygenase $(C A O)$ gene identified the key enzyme for the formation of chlorophyll b in Chlamydomonas reinhardtii [13]. Subsequently, homologous genes in Arabidopsis thaliana (AtCAO) and Oryza sativa (OsCAO1 and OsCAO2) were characterized [14] [15]. A mutation in this enzyme causes a pale green phenotype with unstable light-harvesting complex II (LHCII) proteins.

Another important enzyme in the biosynthetic pathway of chlorophyll is chlorophyll synthase, which catalyzes the esterification of chlorophyllide, the last step in the synthesis of chlorophyll. In rice, the gene ygl1 (yellow-green leaf1) was identified as encoding this enzyme. Mutation of this gene results in a yellowish-green color in young leaves, decreased chlorophyll synthesis, increased levels of tetrapyrrole intermediates and the arrest of chloroplast development [16] [17].

Mutations associated with the development and differentiation of chloroplasts have also been described: For example, $d c l$ (defective chloroplast leaves) is a gene involved in the morphogenesis and development of chloroplasts, which is located within the palisade cells of tomato leaves [18]. Mutations in the dag (differentiation and greening) gene of Antirrhinum majus block chloroplast development, which, in turn, results in white, re- 
versible sectors in the leaves [19]. The correct expression of this gene is required for expression of chloroplast-targeted nuclear genes such as $c a b$ (chlorophyll a/b-binding protein) and $r b c$ (ribulose-1,5-bisphosphate carboxylase/oxygenase small subunit) genes.

Disruption of the cla-1 (chloroplasts altered) gene in Arabidopsis thaliana affects the expression of the other photosynthesis-related genes encoded in the nucleus and in the chloroplast [20]. Plastids with mutations in $d c l$, dag and cla-1 are arrested in a state of proplastid, while some plastids of an albino mutant in barley remain completely devoid of an internal membrane system, except for vesicles; vesicle formation occurs because the mutations affects the formation of thylakoids [21] [22].

Mutants altered in any step of chlorophyll synthesis or chloroplast biogenesis represent important experimental models for studying the biochemistry, physiology and genetics of these biological processes. These mutants can be obtained spontaneously or can be induced from plant tissue or cells cultured in vitro [23]. Unfortunately, many of the chlorophyll mutants obtained so far are lethal (for example, the albino mutants) and, consequently, they can only be studied for a brief time, i.e., the early stages of development. Maintenance and reproduction of these mutants in vitro is only feasible under heterotrophic growing conditions.

This paper presents the physiological and ultrastructural description of a unique, chlorophyll-deficient cell line that presents a yellow phenotype and grows under heterotrophic conditions. This mutant was obtained spontaneously from the chlorophyllic cell system of the highly drought tolerant blue grama grass (Bouteloua gracilis (Kunth) Lag. ex Griffiths), an exceptional model within the cereals [24]. Although chlorophyll-deficient mutants has been reported for monocots, no chlorophyllic cell line has been described up to now for graminaceous (cereal) species besides that described by Aguado-Santacruz et al. in 2001. Consequently, without a parental, wild-type chlorophyllic cell line, the identification and further molecular, biochemical or physiological description of chlorophyll deficient mutants cell lines in cereals is not possible.

Based on the results presented here, we suggest that the dual model, (i.e., the parental wild-type green cells and the complementary chlorophyll-deficient cell mutant system) represents an excellent resource for the study of different molecular, biochemical, physiological processes of plants, including the study of chlorophyll synthesis, carbohydrate metabolism, light photosynthetic reactions, and chloroplast structure and development, as well as the analysis of the chloroplast response to abiotic stress.

\section{Materials and Methods}

\subsection{Plant Cell Culture}

The mutant, yellow cell culture utilized in this study was obtained from a green cell line previously generated by our research group. A yellowish cell clump spontaneously formed within the green cell masses and then it was isolated and cultured on solid medium having the same components of the medium employed for growing the wild-type, green cells. After four months, these cells maintained their yellow phenotype and were transferred to liquid medium and subcultured every 10 days.

To characterize this mutant, yellow cell line, growth kinetics were performed for the green wild-type cell line and the yellow mutant cell line in batch cultures for 12 days. As starting material, cells were collected 8 days after their inoculation into fresh liquid medium, using a filtration system. Twenty-five Erlenmeyer flasks (125 mL capacity; 25 flasks per treatment) were filled with $24 \mathrm{~mL}$ of growing medium and then inoculated with $0.4 \mathrm{~g}$ of cells (green or yellow). Inoculated flasks were shaken at 90 rotations per minute and incubated in a growth chamber with $77 \mu \mathrm{mol}$ (photon) $\mathrm{m}^{-2} \cdot \mathrm{s}^{-1}$ of continuous light (provided by cool fluorescent lamps), $30^{\circ} \mathrm{C} \pm 1{ }^{\circ} \mathrm{C}$ and 33.8\% relative humidity. During the growth kinetics, five inoculated flasks were sampled at 0, 3, 6, 9 and 12 days to analyze the variables of fresh weight, dry weight, chlorophyll, and carotenoids.

\subsection{Fresh and Dry Weight Determinations}

Fresh weight was determined on an analytical scale, after separating the cell biomass from the liquid medium by filtration; excess medium was removed using a bed of paper towel. After determining the fresh weight, samples were dried in an oven for $48 \mathrm{~h}$ at $60^{\circ} \mathrm{C}$ and then weighed on an analytical scale to obtain the dry weight.

\subsection{Quantification of Chlorophylls}

Quantification of chlorophylls was carried out following the Arnon [25] protocol. Briefly, 0.04 to $0.06 \mathrm{~g}$ of cells 
previously frozen at $-80^{\circ} \mathrm{C}$ were ground with $1 \mathrm{~mL}$ ice cold $80 \%$ acetone $(\mathrm{v} / \mathrm{v})$. Then, the pigment extract was centrifuged at $4000 \mathrm{~g}$ for $10 \mathrm{~min}$. The supernatant was then recovered for chlorophyll quantification by spectrophotometry. Chlorophyll concentrations were calculated from standard curves previously elaborated with chlorophyll $a$ (Sigma, St Louis, MO Catalog number C6144) and chlorophyll $b$ (Sigma, St Louis, MO Catalog number C5878). Chlorophylls $a$ and $b$ were quantified by absorbance at $663 \mathrm{~nm}$ and $645 \mathrm{~nm}$, respectively.

\subsection{Quantification of Carotenoids}

Quantification of carotenoid pigments was based on the method proposed by the AOAC [26]. Briefly, 0.1 to $0.15 \mathrm{~g}$ of cells previously frozen at $-80^{\circ} \mathrm{C}$ were ground with $4.75 \mathrm{~mL}$ of a solvent mixture (hexane: ethanol: acetone: toluene; 10:6:7:7 v/v). Subsequently, the mixture was stirred for 3 min using a vortex, and then one drop of distilled water, and $0.5 \mathrm{~mL}$ of a $40 \%$ methanolic solution of $\mathrm{KOH}$ were added. The samples were stirred for $16 \mathrm{~h}$ at room temperature. After this time, $3.75 \mathrm{~mL}$ of hexane were added, and the resulting mixture was stabilized in the dark for $1 \mathrm{~h}$. The upper phase was subsequently recovered for the determination of the carotenoids by spectrophotometry. The carotene fraction was quantified by absorbance at $436 \mathrm{~nm}$, whereas the total xanthophylls were determined at $474 \mathrm{~nm}$.

\subsection{Transmission Electron Microscopy (TEM)}

Transmission electron microscopy was carried out following the protocol proposed by Zavaleta-Mancera et al. [27]. Briefly, After eight days of growth, wild-type and yellow mutant cells were fixed overnight at $4^{\circ} \mathrm{C}$ in a $2.5 \%$ glutaraldehyde fixing solution prepared with a $0.1 \mathrm{M}$ phosphate buffer ( $\mathrm{pH} 7.2$ ). The samples were then washed with phosphate buffer. Post-fixation was performed using osmium tetroxide (1\%) for $2 \mathrm{~h}$ at room temperature. After this period, the samples were washed twice with phosphate buffer and dehydrated in an ethanol series of $30 \%, 40 \%$, 50\%, 60\%, 70\%, 80\%, 90\% and 100\%. Dehydrated cells were included in LR White resin (Electron Microscopy Science, Catalog number 14,380) and sectioned on an ultramicrotome (Ultracut, Reichert-Jung). Microscopy analysis was conducted on a transmission electron microscope (JEOL $1200 \mathrm{EX}$ II) operated at $70 \mathrm{kV}$.

\section{Results}

\subsection{Growth of the Wild-Type, Green Cells and the Novel Mutant, Yellow Cells}

The novel cell line described in this paper spontaneously appeared in our previously described chlorophyllic cell system. This mutant line exhibits a yellowish phenotype and is routinely cultured in the same media (liquid and solid) employed for growing the wild-type green cells (Figure 1). Cell growth kinetics were conducted with the wild-type, chlorophyllic and the yellow mutant cell lines and showed differences in biomass gain measured in terms of fresh and dry weights.

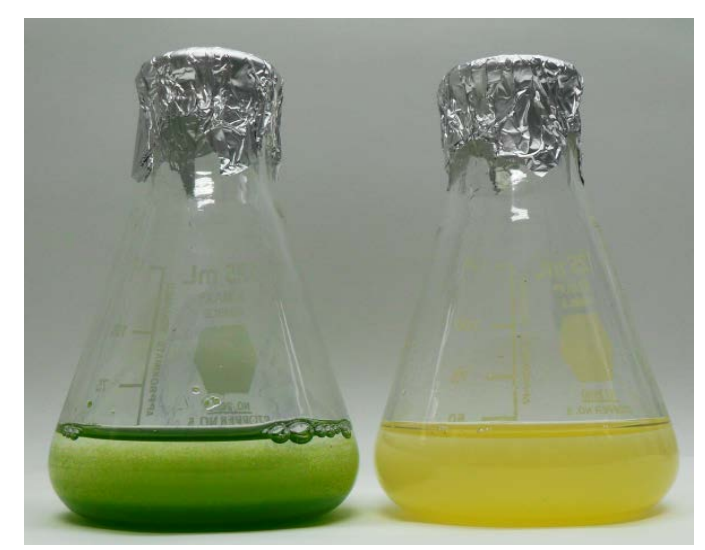

Figure 1. Phenotypes of the Bouteloua gracilis plant cell cultures. A wild-type with green cells is shown on the left and a mutant cell line with yellow cells is shown on the right. Both cell lines are cultivated in the same growing media and environmental conditions. 
Throughout the cell kinetics studies, the fresh weight gain was higher in the chlorophyllic cell line than in the mutant line, with the largest differences found at 9 and 12 days (Figure 2(A)). These data reflect a reduction in growth ranging between $16.4 \%$ and $32.4 \%$ in mutant cells relative to the wild-type cell line. The behavior of cells in terms of dry weight was similar to that observed for fresh weight kinetics (Figure 2(B)), but in this case, the dry weight reduction of the yellow mutant cells ranged between $8 \%$ and $15 \%$, indicating that water accumulation accounted for the greater differences observed in terms of fresh weight.

The values for the fresh and dry weights gathered during the cell growth kinetics in both cell lines were adjusted to a logistic model for batch culture, and then the doubling times were calculated. The wild-type cell line showed doubling times in biomass at 1.24 and 1.17 days for fresh and dry weight, respectively, whereas the yellow mutant cells took longer to increase their biomass, showing doubling times of 1.39 and 1.22 days for fresh and dry weight, respectively. Thus, from these data is clear that proper assemblage of photosynthetic pigments is fundamental for cell growth.

\subsection{Chlorophyll and Carotenoids}

Chlorosis is a critical and visible symptom of almost all chlorophyll-deficient mutants which is and is observed in higher plants and other photosynthetic organisms. To characterize the new cell line possessing a chlorophyll-deficient phenotype, we determined the chlorophyll $a$, chlorophyll $b$, total chlorophyll and carotenoid contents in both yellow mutant and wild-type green cell lines.

Pigment analysis demonstrated the presence of chlorophylls $a$ and $b$ in the mutant cells but at much lower levels than those found in wild-type cells (Figure 3). The contents of chlorophyll $a, b$ and total in wild-type cells were higher at the beginning of cell growth and then decreased by day 3 . This reduction in chlorophyll concentration is strongly linked to the availability of sucrose in the culture medium (3\%) because this carbohydrate (like many others) inhibits chlorophyll synthesis both in whole plants and in chlorophyllic cell systems [28] [29].

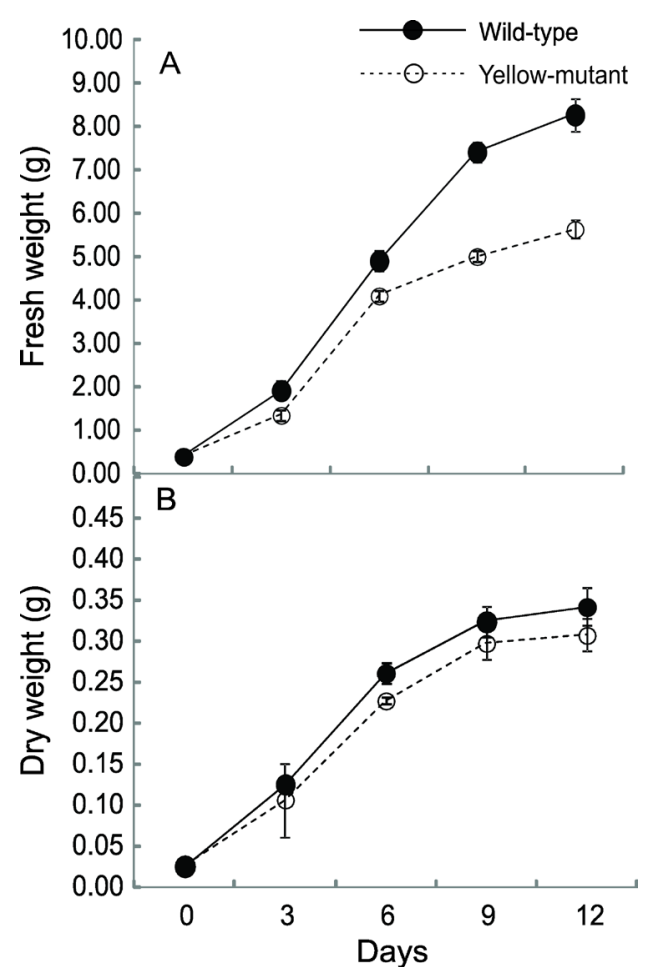

Figure 2. Fresh and dry mass kinetics in the yellow-mutant and wild-type cell lines grown in batch culture. Points represent the mean of five replicates from three independent experiments \pm Standard Error. 


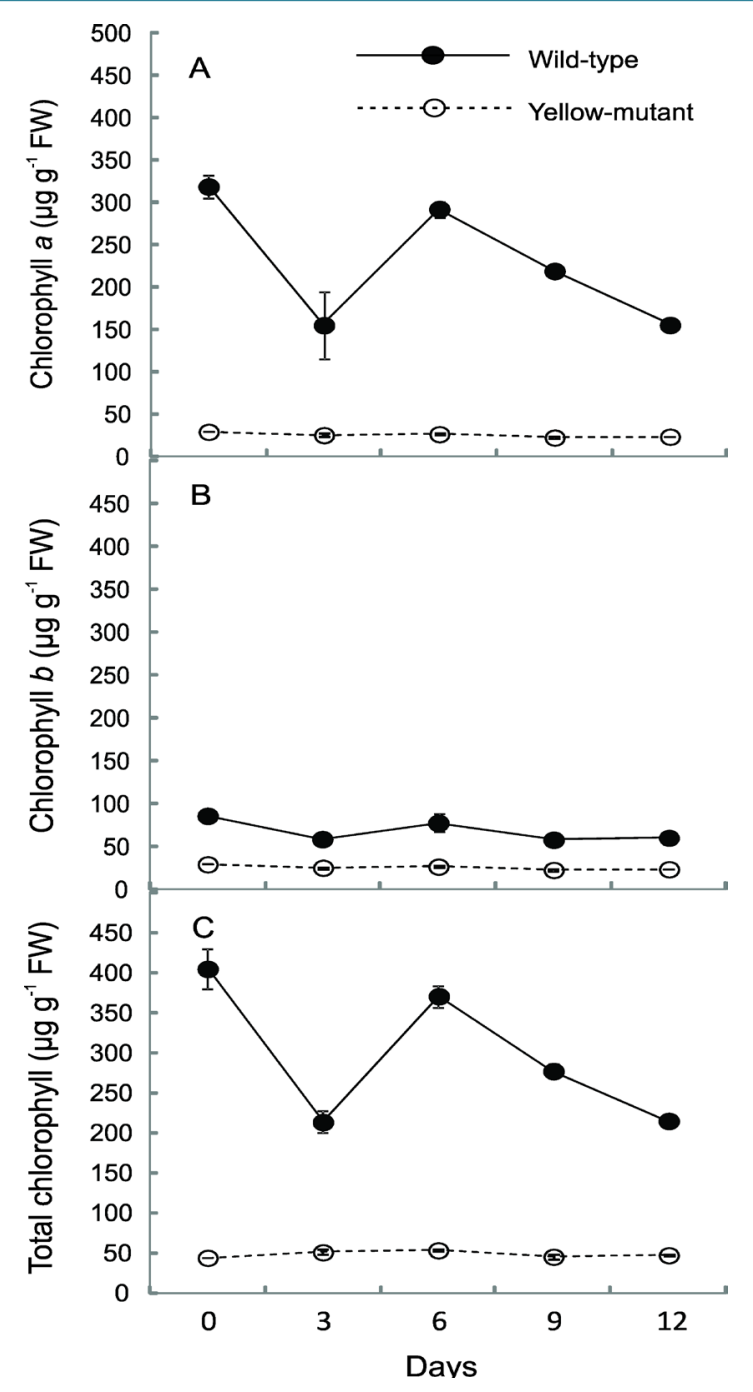

Figure 3. Chlorophyll kinetics in the yellow mutant and green wild-type cell lines. Points represent the mean of five replicates from three independent experiments \pm Standard Error.

After this chlorophyll decline, sucrose consumption by the cells allowed maximum accumulation of chlorophyll ( $a, b$ and total) at day 6 of the cell kinetics at levels very similar to day zero. The wild-type green cell line accumulated $292.8 \mu \mathrm{g} \cdot \mathrm{g}^{-1} \mathrm{FW}$ of chlorophyll $a$, while the mutant cell line only attained $27.1 \mu \mathrm{g} \cdot \mathrm{g}^{-1} \mathrm{FW}$; this value represents only $9.3 \%$ of the chlorophyll synthesized by the wild-type cell line (Figure 3(A)). The accumulation of chlorophyll $b$ in the mutant cells was less affected than chlorophyll $a$ because the mutant cells synthesized $29.9 \mu \mathrm{g} \cdot \mathrm{g}^{-1} \mathrm{FW}$, whereas the chlorophyllic cells accumulated $78.1 \mu \mathrm{g} \cdot \mathrm{g}^{-1} \mathrm{FW}$; this accumulation represented 38.2\% of the chlorophyll $b$ produced by the wild-type green cells (Figure 3(B)).

Because of the above-mentioned differences, the total chlorophyll was almost eleven-fold higher in the wildtype cells than in the mutant cells (Figure 3(C)). Following the course of the experiment, we observed a decrease in the concentration of these pigments by days 9 and 12 of the cell growth kinetics; this reduction is due to nutrient exhaustion and an accumulation of toxic compounds at the final phase of the senescing batch cultures.

Carotenoids are essential components of the photosynthetic machinery and play a critical role in preventing photo-oxidative damage [30] [31]. Several studies have shown that deficiency of chlorophyll is highly correlated to the deficiency in the content of carotenoid pigments. Therefore, we analyzed if the low chlorophyll content found in the yellow mutant also correlated to carotene and xanthophyll content in this mutant. 
As anticipated, these pigments were present in the mutant cells at very small levels. Similarly to the chlorophyll behavior, there was a decrease in the concentration of carotenes and xanthophylls at day 3 of the cell kinetics and then they reached their maximum concentration at day 6 in both the wild-type and yellow mutant cell lines. The maximum concentration of carotenoids in the wild-type cell line was $54.9 \mu \mathrm{g} \cdot \mathrm{g}^{-1} \mathrm{FW}$, while in the mutant this value was $4.4 \mu \mathrm{g} \cdot \mathrm{g}^{-1} \mathrm{FW}$ (Figure 4(A)). The content of carotenoids in the mutant cells represented only $8 \%$ of the amount accumulated by the green cells. On the other hand, the xanthophylls accumulated 47.4 $\mu \mathrm{g} \cdot \mathrm{g}^{-1} \mathrm{FW}$ in the wild-type cells, whereas the yellow mutant cells only reached $2.7 \mu \mathrm{g} \cdot \mathrm{g}^{-1} \mathrm{FW}$ (Figure 4(B)), which represents $5.6 \%$ of the total xanthophylls accumulated by the wild-type cells.

\subsection{Bright Field and Ultrastructural Characterization}

To analyze a probable relationship between the deficiency of photosynthetic pigments with the organization and structure of the plastids in the mutant cell line, we studied the structure of these organelles both in the yellow mutant and in the green wild-type cell lines. Bright field microcopy showed few or no membrane organization in the yellow, mutant cells, while well-developed chloroplasts were visualized in the wild type green cells (Figure 5). To deepen into the structural differences between the green cells and the yellow cells an ultrastructural analysis was carried out. Electron microscopy analysis showed chloroplasts possessing a normal organization of grana thylakoids and stroma lamellae in the chlorophyllic wild-type cells (Figures 6(A)-(C)); the observed size of the chloroplasts found in the green cells was $3.88 \pm 0.20 \mu \mathrm{m}$, which is very close to the chloroplast size reported for cells of mature leaves [32] [33].

On the contrary, the mutant cells did not develop chloroplasts. Instead, we found etioplast-like organelles with an internal structure similar to a prolamellar body (Figure 6(D) \& Figure 6(E)). The etioplast-like plastid type we observed in our mutant cell line was smaller than chloroplasts found in wild-type cells (1.76 \pm 0.32 versus $3.88 \pm 0.20 \mu \mathrm{m}$ ), but they were similar in size to rice etioplasts [34]. Moreover, this mutant cell line also possessed other types of plastids with poorly developed membranes, which formed vesicular structures in some cases (Figure 6(F) \& Figure 6(G)). The average size of these organelles was $2.46 \pm 0.10 \mu \mathrm{m}$. These results indicate that the plastids developed by the mutant cells were abnormal and severely damaged in their membrane structure and organization, thus preventing the accumulation of chlorophyll and accessory pigments.

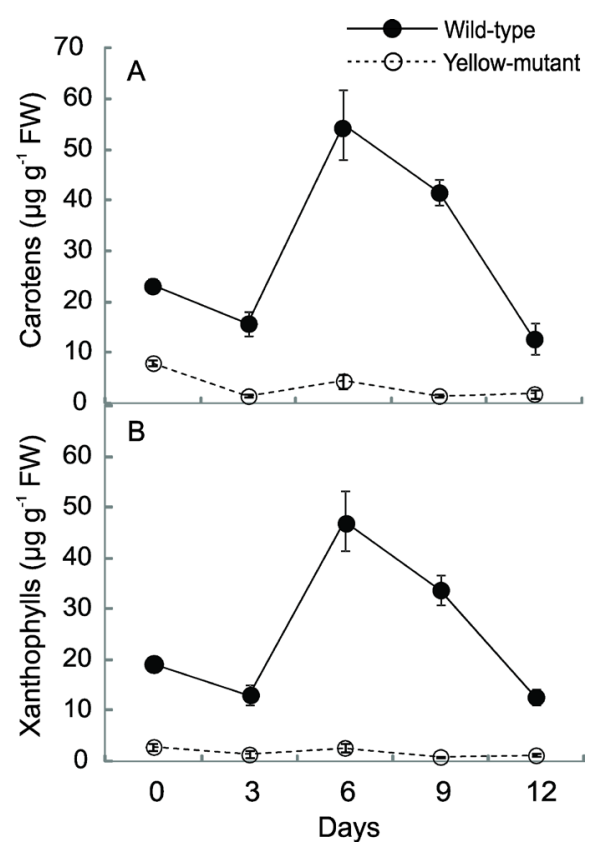

Figure 4. Carotens and xanthophylls kinetics in the yellow-mutant and green wild-type cell lines. Points represent the mean of five replicates from three independent experiments \pm Standard Errors. 


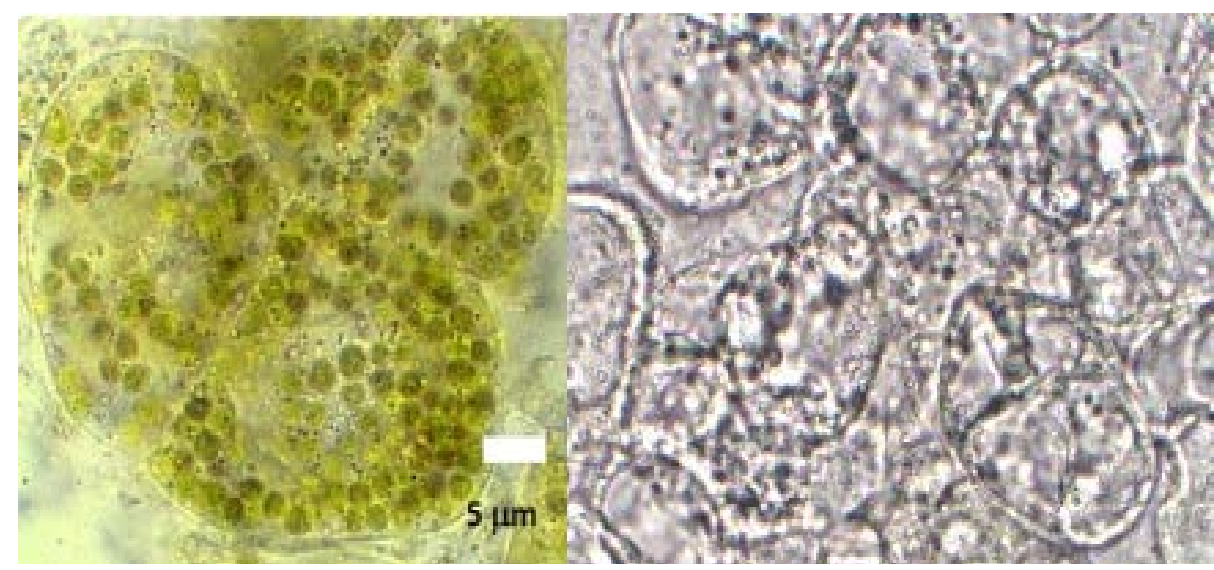

Figure 5. Brigh field microscopy analysis of the Bouteloua gracilis cells lines. The structure of a wild-type, green cell culture is shown on the left, while the aspect of a mutant, yellow cell culture is shown on the right.
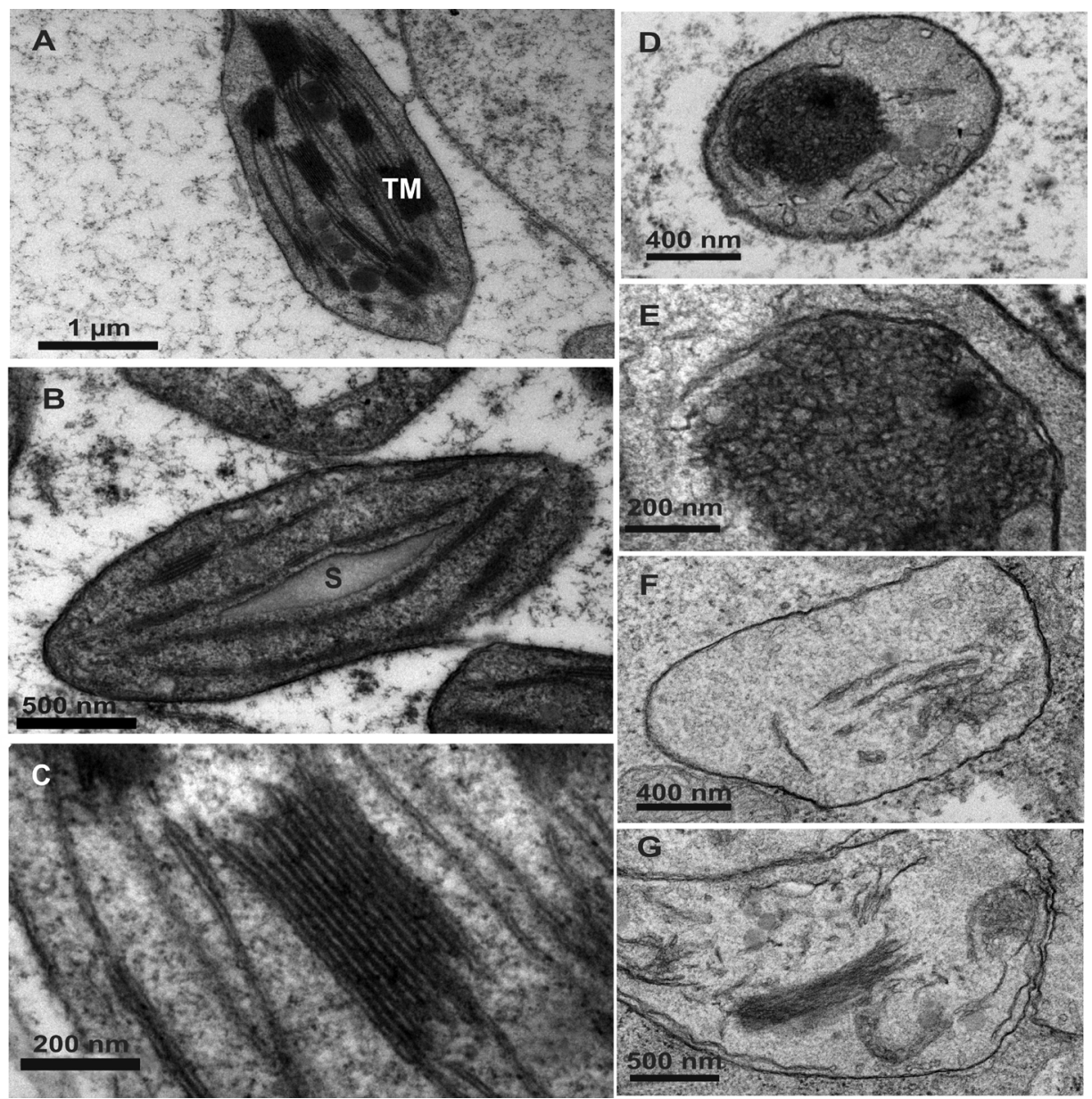

Figure 6. Plastids in green wild-type cells (A)-(C) and yellow mutant cell line (D)-(G) of $B$. gracilis. Chloroplasts formed in the wild type, green cells are around $4 \mu \mathrm{m}$ in mayor axis and $1.5 \mu \mathrm{m}$ in minor axis (A) and formed starch (B) and well-developed and organized thylakoidal membranes (C). Etioplast-like plastids with structure similar to a prolamellar body were formed in the mutant cells (D) (E). Other type of plastids was present in the mutant line, which have poorly-developed membrane systems, possibly because of low photoprotective pigment synthesis (F)-(G). S, Starch; TM, Thylakoidal membrane. 


\section{Discussion}

In general, most mutants deficient in the production of photosynthetic pigments exhibit slow growth and low productivity. Although these mutations commonly affect the synthesis of photosynthetic machinery components, primarily chlorophylls and carotenoids, they can also affect the stability of the pigment-protein complexes, the components of electron chain, and other structural components of the chloroplasts.

According to our results, the cell lines studied here showed very contrasting differences in structure, physiology and biochemistry. First, great differences in fresh weight and dry weight gains between the yellow mutant and the wild-type cells were evident during the course of the growth kinetics, particularly in the fresh weight attained at day nine and 12. Differences in both fresh and dry biomass accumulation between these cell lines were reflected in the doubling times; cells having well-developed chloroplasts sustained a faster growth. Studies in our lab indicate that although the green cells were not completely photoautotrophic, their chloroplasts supplied some energy and carbon skeletons for maintaining better growth in the green cells, i.e., the cells were photomixotrophic (data not shown). These cells not only metabolized the reduced carbon present in the culture medium but also had functional chloroplasts with the ability to fix carbon from the air.

In contrast, poor development of the photosynthetic machinery in the mutant yellow cells implies that they depended entirely on the carbon source supplied in the growing medium. The carbon source in the culture medium is limited and therefore rapidly consumed due to the increase in energy demand for cellular growth. However, the role of the chloroplast in the cell physiology and biochemistry is not restricted to carbohydrate metabolism because a number of important biomolecules including amino acids, hormones, fatty acids and nucleotides are manufactured and stored in this compartment. Additionally, the chloroplast is also a site of significant uptake of elements such as sulfur [35] and nitrogen [36]. Chlorophyll deficiency is closely related to arrested development of chloroplasts. Defective chloroplasts can alter any of these important metabolic pathways that affect subsequently the growth of the mutant cells [37]. For example, the mutant chd6 of Vitisvinifera maintained in vitro attained low dry matter and carbohydrate accumulation and showed signs of blockage in $\mathrm{CO}_{2}$ fixation as well as impaired mobilization and accumulation of soluble carbohydrates during growth and development. This mutant showed slow growth, dwarfism and small leaves during its growth cycle [38].

One possibility for the low accumulation of chlorophyll in YELP mutant is that one of the steps of chlorophyll biosynthesis is partially blocked. Various types of mutants are characterized by a deficient accumulation of chlorophyll caused by blockage of specific steps in the biosynthetic pathway of this pigment [39]. Several authors have emphasized two key points of control for this process.

One of the control steps is the synthesis of 5-aminolevulinicacid (ALA) in the first stage of chlorophyll formation in the plastids, which is easily broken because the biosynthetic pathway of ALA requires enzymes and substrates encoded in the nucleus and chloroplast [40]. Mutations associated with this first control point have been primarily characterized in mutants with variegated green and white sectors in the leaves of Euonymus japonicas [41] and in an albino mutant of barley [42]; these mutants do not synthesize chlorophyll. In contrast, other mutants affected in the ALA biosynthesis such as xantha-702 in cotton, and chlorine 5 in sunflower, synthesize chlorophyll at very low levels, approximately 3\% in xantha-702 and 50\% in chlorine-5 relative to wild-type plants [43] [44]. The results of this work demonstrate that our mutant accumulated low levels of chlorophyll, approximately $9 \%$ of the concentration found in the wild-type cells. Thus, we believe that the yellow mutant studied was defective at this point in the chlorophyll biosynthesis pathway. However, in this study we did not determine the levels of ALA or other intermediates in the yellow mutant. Furthermore, in plant tissues, light is required for the continuous synthesis of ALA, and our mutant cell line grows under continuous light, so it is possible that it can accumulate certain levels of ALA.

The other control point during the synthesis of chlorophyll is the reduction of protochlorophyllide (Pchlide) to chlorophyllide [45]. This light-dependent step is catalyzed by the enzymeproto chlorophyllide oxidoreductase (POR). The POR enzyme forms aggregates of ternary complexes composed by light-dependent POR bound to its substrate and cofactor, Pchlide and NADPH, respectively. These aggregate photoreduce Pchlide molecules under flash illumination pulses (shorter than 2 milliseconds). POR possesses unique features such as its lightdependent catalytic activity, accumulation in plastids of dark-grown angiosperms (etioplasts) via binding its substrate, Pchlide, and the cofactor NADPH, resulting in the formation of prolamellar bodies and rapid degradation under subsequent illumination.

Alteration in the contents of some of the components of the complex POR: Pchlide: NADPH has negative ef- 
fects on the synthesis of chlorophyll. Most of these abnormalities are caused by mutations that affect various steps in the pathway of tetrapyrrole compounds and not directly in the synthesis of the POR enzyme or substrate. For example, the NYB (Nanchong Yellow Barley) mutant affected in the import of POR into the chloroplasthaslimited capacity for chlorophyll synthesis due to decreased POR in the plastid. Consequently, this mutant shows yellow leaves containing developmentally-arrested chloroplasts with few membrane systems [46]. Additionally, the phytochrome-deficient mutants of tomato aurea (au) and yellow-green-2 (yg-2) show inhibition of Pchlide synthesis, which in turn, causes loss of the POR protein in these mutants [47]. Under white light, $a u$ and $y g-2$ mature plants present a pale phenotype due to lower chlorophyll levels and reduced chloroplast development [48] [49].

Because the prolamellar body is the main site of accumulation of Pchlide and POR complexes, studies aimed to characterize this protein and its substrate in the new mutant YELP presented here will be required because we found plastids with prolamellar body-like structures despite the yellow cells were always grown in the light. In addition, it will be also important to analyze the intermediaries or the precursors of the later stages of ALA synthesis, prior to the Pchlide reduction.

Carotenoids are structural and functional components of the chloroplasts, which help in the light capture in the reaction centers and in light-harvesting complexes, extending the spectrum of light absorption into the blue and green regions [50]. Molecular studies have been performed with mutants affected indifferent points of the carotenoidbio synthesis pathway (for example, mutations in the $p d s 3$ gene, which encodes the enzyme phytoene desaturase in Arabidopsis thaliana). The pds3 mutant showed that the expression of other nuclear genes that encode proteins targeted to the chloroplast were mainly involved in photosynthesis; these alterations coincided with chloroplasts having a severely retarded development. The psd3 mutant has approximately 20 metabolic pathways affected with some of the light-dependent routes completely disrupted. Photosynthesis is not functional in this mutant due to chlorophyll loss and alterations in the Calvin cycle. Without photosynthesis, this mutant survives only by the external supply of carbon in the culture medium [51].

On the other hand, carotenoids are also involved in photoprotection by quenching singlet oxygen and other reactive species. Reduced carotenoid synthesis causes photo-oxidative damage, particularly under high-light conditions or extreme temperatures. However, in carotenoid-deficient plants, even standard light conditions trigger photo-oxidation [52].

Different mutations resulting in chlorophyll-deficient phenotypes correlate with disorders in chlorophyll synthesis or chloroplast development which are identified visually by abnormal coloration. This article describes a mutant isolated from a highly chlorophyllous cell culture. This cell line is the result of a spontaneous mutation producing a yellow phenotype with very low chlorophyll contents (Figures 2(A)-(C)). Mutations that cause the deficiency or lack of chlorophyll are closely related to the disruption of chloroplast structure and consequently to the loss of function [53] [54]. In many cases, the chloroplasts are arrested at very early stages of development as in the case of the proplastid state in dcl mutants of tomato [55], dag mutants in Antirrinhum majus [56] and cla1 mutants in Arabidopsis thaliana [57].

The low capacity of this yellow mutant for accumulating chlorophyll correlated with a failure in the structure and organization of the chloroplast. This new yellow mutant possessed plastids with disorganized and poorly developed membranes and presented etioplast-like plastids with a structure similar to a prolamellar body. This disruption was not corrected by the exposure of these yellow cells to the light. It is very interesting to note that these organelles were present in the mutant cells growing in the light because etioplasts are plastids characteristic of plants grown in the dark, although they are devoid of chlorophyll and develop a unique inner membrane network conforming the prolamellar body. In contrast, the yellow mutant described here accumulated chlorophyll and carotenoids though a very low levels. In this connection it is important to point out the existence of another type of plastids occurs under natural conditions, named etio-chloroplasts. Etio-chloroplasts contain chlorophylls and small prolamellar bodies interconnected with chloroplast thylakoids. Several studies favor the involvement of etioplasts and etio-chloroplasts as intermediary stages in chloroplast formation under natural conditions [58].

The occurrence of the prolamellar body-like structure in the YELP mutant of B. gracilis is intriguing because this mutant is commonly grown under continuous light conditions, and this structure is indicative of plastid development in the dark. Illumination of etioplasts initiates the dispersal of the prolamellar body and the formation of thylakoid membranes where the chlorophyll a/b-binding protein and chlorophyll form the pigment-protein complexes of the photosynthetic apparatus. This transitional process is very complicated because it involves 
different processes such as chloroplast development, pigment synthesis, and the assemblage of the photosystems in thylakoids, all of which are accomplished by and depend on the differential expression of a large number of genes [59] [60]. There is a close connection between the chloroplast development and formation of thylakoidal membranes [61]. Different mutants affected in the formation of thylakoidal structures have been described in Arabidopsis among them vipp1, mgdg1 and Thf1. Some of the main characteristics of these mutants include the formation of plastids containing vesicular structures, disordered membranes and the presence of membrane invaginations. Interruption of the vipp1 (vesicle-inducing protein in plastids 1) locus gene, results in a complete loss of thylakoid membranes [62]. The mgdg1 mutants arrest at the step of enzyme formation of monogalactosyldiacylglycerol (MGDG) synthase [63].

These mutants produce albino seedlings in presence of sucrose, and mgdg 1 plastids only have invaginations from the plastid envelope. Wang et al. [64] described the mutant Thf1 (Thylakoid formation 1). This mutation produces dwarf-variegated plants, where green sectors contain plastids with vesicular structures and other disorganized membranes.

The blockage of chloroplast development at the etioplast stage with persistence of the prolamellar body in the light is unusual. Bachmann et al. [65] reported the formation of stable prolamellar bodies in an F1 heterozygote obtained from the cross of albino and pastel mutants of maize. This maize mutant was deficient in carotenoid biosynthesis, which resulted in the loss of the majority of chlorophyll by photo-oxidation. A similar phenotype was reported for wheat seedling streated with amitrole [66], an herbicide that blocks the carotenoid synthesis in plants.

The YELP mutant described in this study synthesized very low levels of carotenoids. Thus, the low quantities of these accessory pigments would also explain why the mutant has plastids with poorly developed internal membranes. However, future studies are needed to analyze the precursors in the biosynthesis pathway of carotenoids, as in the case of the mutant of maize and the wheat seedlings treated with amitrole, to establish whether a blockage in the carotenoid pathway is a key factor inducing the yellow phenotype of the mutant cells of $B$. gracilis.

Totest this hypothesis, the differential ability of the mutant to accumulate chlorophyll under lowlight intensity and high luminosity should be analyzed. If chlorophyll synthesis is strongly linked to photo protection conferred by the carotenoid content, then higher chlorophyll content should be expected in cells grown under low light. According to the analysis of the content of chlorophylls and carotenoids, the persistence of low chlorophyll amounts in our mutant indicates that even limited synthesis of carotenoids may prevent complete photo-oxidation of chlorophyll.

\section{Conclusion}

In conclusion, the novel YELP mutant does not develop chloroplasts, instead possess two types of plastids: etioplasts-like organelles and others with poorly developed membranes. As a consequence, the YELP cells accumulated very small levels of chlorophyll and carotenoids. The parental wild-type green cells and the complementary chlorophyll-deficient cell mutant system represent an excellent model for the analysis of plastids development and differentiation. But, beyond to this issue, our research group is interested in studying the role of chloroplast in the response of these cells to abiotic stress, e.g. osmotic stress. Since previous study has shown that osmotic stress caused by polyethylene glycol results in an increase of chlorophyll content in green cells [67]. Thus YELP mutant comes to form a dual model that could help clarify several questions about the role of the chloroplast in the response to abiotic stress of B. gracilis cell line.

\section{Acknowledgements}

The first author gratefully acknowledges the scholarship from CONACyT (Consejo Nacional de Ciencia y Tecnología) to pursue her postgraduate studies. This work received partial financial support from the Consejo Nacional de Ciencia y Tecnología (CONACyT) by project 82390 and from the Colegio de Postgraduados (Fideicomiso revocable de administración e inversión No. 167304).

\section{References}

[1] Yu, F., Fu, A., Aluru, M., Park, S., Xu, Y., Liu, H., Liu, X., Foudree, A., Nambogga, M. and Rodermel, S. (2007) Variegation Mutants and Mechanism of Chloroplast Biogenesis. Plant, Cell and Environment, 30, 350-365.

http://dx.doi.org/10.1111/j.1365-3040.2006.01630.x 
[2] Gustafsson, A. (1940) The Mutation System of the Chlorophyll Apparatus. Kgl. Fys. Sällsk. Handl. (Lund). Bd., 51.

[3] Jarvis, P., Dörmann, P., Peto, C.A., Lutes, J., Benning, C. and Chory, J. (2000) Galactolipid Deficiency and Abnormal Chloroplast Development in the Arabidopsis MGD Synthase 1 Mutant. Proceedings of the National Academy of Science of the United States of America, 97, 8175-8179. http://dx.doi.org/10.1073/pnas.100132197

[4] Kessler, F. and Schnell, D. (2009) Chloroplast Biogenesis: Diversity and Regulation of the Protein Import Apparatus. Current Opinion in Cell Biology, 21, 494-500. http://dx.doi.org/10.1016/j.ceb.2009.03.004

[5] Gutiérrez-Nava, M., Gillmor, C.S., Jiménez, L.F., Guevara-García, A. and León, P. (2004) Chloroplast Biogenesis Genes Act Cell and Noncell Autonomously in Early Chloroplast Development. Plant Physiology, 135, 471-482. http://dx.doi.org/10.1104/pp.103.036996

[6] Qin, J., Gu, H., Ma, L., Peng, Y., Deng, X.W., Chen, Z. and Qu, L.J. (2007) Disruption of Phytoene Desaturase Gene Results in Albino and Dwarf Phenotypes in Arabidopsis by Impairing Chlorophyll, Carotenoid, and Gibberellins Biosynthesis. Cell Research, 17, 471-482. http://dx.doi.org/10.1038/cr.2007.40

[7] Gu, J., Miles, D. and Newton, K.J. (1993) Analysis of Leaf Sectors in the NCS6 Mitochondrial Mutant of Maize. The Plant Cell, 5, 963-971. http://dx.doi.org/10.1105/tpc.5.8.963

[8] Biswal, A.K., Pattanayak, G.K., Pandey, S.S., Leelavathi, S., Reddy, V.S., Govindjee and Tripathy, B.C. (2012) Light Intensity-Dependent Modulation of Chlorophyll b Biosynthesis and Photosynthesis by Overexpression of Chlorophyllidea Oxygenase in Tobacco. Plant Physiology, 159, 433-449. http://dx.doi.org/10.1104/pp.112.195859

[9] Du, Y.Y., Chen, H., Zhong, W.L., Wu, L.Y., Ye, J.H., Lin, C., Zheng, X.Q., Lu, J.L., and Liang, Y.R. (2008) Effect of Temperature on Accumulation of Chlorophylls and Leaf Ultrastructure of Low Temperature Induced Albino Tea Plant. African Journal of Biotechnology, 7, 1881-1885.

[10] Imsande, J. (1998) Iron, Sulfur, and Chlorophyll Deficiencies: A Need for an Integrative Approach in Plant Physiology. PhysiologiaPlantarum, 103, 139-144. http://dx.doi.org/10.1034/j.1399-3054.1998.1030117.x

[11] Jung, K.H., Hur, J., Ryu, C.H., Choi, Y., Chung, Y.Y., Miyao, A., Hirochika, H. and An, G. (2003) Characterization of a Rice Chlorophyll-Deficient Mutant Using the T-DNA Gene-Trap System. Plant Cell Physiology, 44, 463-472. http://dx.doi.org/10.1093/pcp/pcg064

[12] Chekounova, E., Voronetskaya, V., Papenbrock, J., Grimm, B. and Beck, C.F. (2001) Characterization of Chlamydomonas Mutants Defective in the H Subunit of Mg-Chelatase. Molecular Genetics Genomics, 266, 363-373. http://dx.doi.org/10.1007/s004380100574

[13] Tanaka, A., Ito, H., Tanaka, R., Tanaka, N.K., Yoshida, K. and Okada, K. (1998) Chlorophyll a Oxygenase (CAO) Is Involved in Chlorophyll b Formation from Chlorophyll a. Proceedings of the National Academy of Science of the United States of America, 95, 12719-12723. http://dx.doi.org/10.1073/pnas.95.21.12719

[14] Espineda, C.E., Linford, A.S., Devine, D. and Brusslan, J.A. (1999) The AtCAO Gene, Encoding Chlorophyll a Oxygenase, Is Required for Chlorophyll b Synthesis in Arabidopsis thaliana. Proceedings of the National Academy of Science of the United States of America, 96, 10507-10511. http://dx.doi.org/10.1073/pnas.96.18.10507

[15] Lee, S., Kim, J., Yoo, E.S., Lee, C.H., Hirochika, H. and An, G. (2005) Differential Regulation of Chlorophyll a Oxigenase Genes in Rice. Plant Molecular Biology, 57, 805-818. http://dx.doi.org/10.1007/s11103-005-2066-9

[16] Wu, Z., Zhang, X., He, B., Diao, L., Sheng, S., Wang, J., Guo, X., Su, N., Wang, L., Jiang, L., Wang, C., Zhai, H. and Wan, J. (2007) A Chlorophyll-Deficient Rice Mutant with Impaired Chlorophyllide Esterification in Chlorophyll Biosynthesis. Plant Physiology, 145, 29-40. http://dx.doi.org/10.1104/pp.107.100321

[17] Wu, Z.M., Zhang, X., Wang, J.L. and Wan, J.M. (2014) Leaf Chloroplast Ultrastructure and Photosynthetic Properties of a Chlorophyll-Deficient Mutant of Rice. Photosynthetica, 52, 217-222. http://dx.doi.org/10.1007/s11099-014-0025-X

[18] Keddie, J.S., Carroll, B., Jones, J.D.G. and Gruissem, W. (1996) The DCL Gene of Tomato Is Required for Chloroplast Development and Palisade Cell Morphogenesis in Leaves. The EMBO Journal, 15, 4208-4217.

[19] Chatterjee, M., Sparvoli, S., Edmunds, C., Garosi, P., Findlay, K. and Martin, C. (1996) DAG, a Gene Required for Chloroplast Differentiation and Palisade Development in Antirrhinum majus. The EMBO Journal, 15, 4194-4207.

[20] Mandel, M.A., Feldman, K.A., Herrera-Estrella, L., Rocha-Sosa, M. and León, P. (1996) CLA1, a Novel Gene Required for Chloroplast Development, Is Highly Conserved in Evolution. The Plant Journal, 9, 649-658. http://dx.doi.org/10.1046/j.1365-313X.1996.9050649.X

[21] Svensson, J.T., Crosatti, C., Campoli, C., Bassi, R., Stanca, A.M., Close, J.T. and Cattivelli, L. (2006) Transcriptome Analysis of Cold Acclimation in Barley Albino and Xantha Mutants. Plant Physiology, 141, 257-279. http://dx.doi.org/10.1104/pp.105.072645

[22] Eckardt, N.A. (2007) Thylakoid Development from Biogénesis to Senescence and Ruminations on Regulation. The Plant Cell, 19, 1135-1138. http://dx.doi.org/10.1105/tpc.107.052779 
[23] Phillips, R.L, Kaepplert, S.M. and Olhoft, P. (1994) Genetic Instability of Plant Tissue Cultures: Breakdown of Normal Controls. Proceedings of the National Academy of Science of the United States of America, 91, 5222-5226. http://dx.doi.org/10.1073/pnas.91.12.5222

[24] Aguado-Santacruz, G.A., Cabrera-Ponce, J.L., Ramírez-Chávez, E., León-Ramírez, C.G., Rascón-Cruz, Q., Herrera-Estrella, L. and Olalde-Portugal, V. (2001) Establishment, Characterization and Plant Regeneration from Highly Chlorophyllous Embryogenic Cell Cultures of Blue Grama Grass, Boutelouagracilis (H.B.K.) Lag. ex Steud. Plant Cell Reports, 20, 131-136. http://dx.doi.org/10.1007/s002990000293

[25] Arnon, D.I. (1949) Copper Enzymes in Isolated Chloroplasts. Plant Physiology, 24, 1-15. http://dx.doi.org/10.1104/pp.24.1.1

[26] AOAC (1997) Official Method of Analysis of the Association of Official Analytical Chemists. AOAC Inc., Arlington.

[27] Zavaleta-Mancera, H.A., Thomas, B.J., Thomas, H. and Scott, I.M. (1999) Regreening of Senescent Nicotiana Leaves. II. Redifferentiation of Plastids. Journal of Experimental Botany, 50, 1683-1689.

[28] La Rosa, P.C., Hasegawa, P.M., and Bressan R.A. (1984) Photoautotrophic Potato Cells: Transition from Heterotrophic to Autotrophic Growth. Physiologia Plantarum, 61, 279-286. http://dx.doi.org/10.1111/j.1399-3054.1984.tb05909.x

[29] Hardy, T., Chaumont, D., Brunel, L., and Gudin, C. (1987) Photoautotrophic Suspension Cultures I-Obtention of Photoautotrophic Cultures from Euphorbia characias L. Journal of Plant Physiology, 128, 11-19. http://dx.doi.org/10.1016/S0176-1617(87)80177-3

[30] Howitt, C.A. and Pogson, B.J. (2006) Carotenoid Accumulation and Function in Seeds and Non-Green Tissues. Plant Cell and Environment, 29, 435-445. http://dx.doi.org/10.1111/j.1365-3040.2005.01492.x

[31] Cazzonelli, C.I. (2011) Carotenoids in Nature: Insights from Plant and Beyond. Functional Plant Biology, 38, 833-847. http://dx.doi.org/10.1071/FP11192

[32] Mullet, J.E. (1988) Chloroplast Development and Gene Expression. Annual Review of Plant Physiology and Plant Molecular Biology, 39, 475-502. http://dx.doi.org/10.1146/annurev.pp.39.060188.002355

[33] Lopez-Juez, E. and Pyke, K.A. (2005) Plastids Unleashed: Their Development and Their Integration in Plant Development. International Journal of Developmental Biology, 49, 557-577. http://dx.doi.org/10.1387/ijdb.051997el

[34] Zychlinski, A., Kleffmann, T., Krishnamurthy, N., Sjölander, K., Baginsky, S. and Gruissem, W. (2005) Proteome Analysis of the Rice Etioplast. Molecular and Cellular Proteomics, 4, 1072-1084. http://dx.doi.org/10.1074/mcp.M500018-MCP200

[35] Leustek, T., Martin, M.N., Bick, J.A., and Davies, J.P. (2000) Pathways and Regulation of Sulfur Metabolism Revealed through Molecular and Genetic Studies. Annual Review of Plant Physiology and Plant Molecular Biology, 51, 141-165. http://dx.doi.org/10.1146/annurev.arplant.51.1.141

[36] Sugiura, M., Georgescu, M.N., and Takahashi, M. (2007) A Nitrite Transporter Associated with Nitrite Uptake by Higher Plant Chloroplasts. Plant and Cell Physiology, 48, 1022-1035. http://dx.doi.org/10.1093/pcp/pcm073

[37] Gollan, P.J., Tikkanen, M. and Aro, E.M. (2015) Photosynthetic Light Reactions: Integral to Chloroplast Retrograde Signalling. Current Opinion in Plant Biology, 27, 180-191. doi:10.1016/j.pbi.2015.07.006

[38] Yang, D., Li, S., Li, M., Yang, X., Wang, W., Cao, Z. and Li, W. (2012) Physiological Characteristics and Leaf Ultrastructure of a Novel Chlorophyll-Deficient chd6 Mutant of Vitis vinifera Cultured in Vitro. Journal of Plant Growth Regulation, 31: 124-135. http://dx.doi.org/10.1007/s00344-011-9225-9

[39] Nagata, N., Tanaka, R. and Tanaka, A. (2007) The Major Route for Chlorophyll Synthesis Includes [3,8-Divinyl]Chlorophyllide $\alpha$ Reduction in Arabidopsis thaliana. Plant and Cell Physiology, 48, 1803-1808. http://dx.doi.org/10.1093/pcp/pcm153

[40] Von Wettstein, D., Gough, S. and GaminiKannangara, C. (1995) Chlorophyll Biosynthesis. The Plant Cell, 7, 10391057. http://dx.doi.org/10.1105/tpc.7.7.1039

[41] Masuda, T., Takabe, K., Ohta, H., Shioi, Y. and Takamiya, K. (1996) Enzimatic Activities for the Synthesis of Chlorophyll in Pigment-Deficient Variegated Leaves of Euonymus japonicus. Plant and Cell Physiology, 37, 481-487. http://dx.doi.org/10.1093/oxfordjournals.pcp.a028970

[42] Hess, W.R., Sehendel, R., Rüdiger, W., Fieder, B. and Börner, T. (1992) Components of Chlorophyll Biosynthesis in a Barley Albino Mutant Unable to Synthesize $\delta$-Aminolevulinic Acid by Utilizing the Transfer RNA for Glutamic Acid. Planta, 188, 19-27. http://dx.doi.org/10.1007/BF01160708

[43] Ladygin, V.G. (2007) Disturbed Structure and Function of Chloroplasts during Blocked Biosynthesis of 5-Aminolevulinic Acid in the Light. Biology Bulletin, 34, 248-258. http://dx.doi.org/10.1134/S1062359007030065

[44] Rassadina, V., Usatov, A., Fedorenko, G. and Averina, N. (2005) Activity of the System for Chlorophyll Biosynthesis and Structural and Functional Organization of Chloroplast in a Plastoma in Chlorina-5 Sunflower Mutant. Russian Journal of Plant Physiology, 52, 606-615. http://dx.doi.org/10.1007/s11183-005-0090-x 
[45] Thomas, H. (1997) Chlorophyll: A Symptom and a Regulator of Plastid Development. New Phytologist, 136, $163-181$. http://dx.doi.org/10.1046/j.1469-8137.1997.00737.x

[46] Yuan, M., Yuan, S., Zhang, Z.W., Xu, F., Chen, Y.E., Du, J.B. and Lin, H.H. (2010) Putative Mutation Mechanism and Light Response of Protochlorophyllide Oxidoreductase-Less Barley Mutant NYB. Plant and Cell Physiology, 51, 13611371. http://dx.doi.org/10.1093/pcp/pcq097

[47] Terry, M.J, Raitt, C.E., Ryberg, M. and Page, A.M. (2001) Altered Etioplast Development in Phytochrome Chromophore-Deficient Mutants. Planta, 214, 314-325. http://dx.doi.org/10.1007/s004250100624

[48] Koornneef, M., Cone, J.W., Dekens, R.G., O’Herne-Robers, E.G., Spruit, C.J.P. and Kendrick, R.E. (1985) Photomorphogenic Responses of Long-Hypocotyl Mutants of Tomato. Journal of Plant Physiology, 120, 153-165. http://dx.doi.org/10.1016/S0176-1617(85)80019-5

[49] Chory, J., Peto, C.A., Ashbaugh, M., Saganich, R., Pratt, L.H. and Ausubel, F.M. (1989) Different Roles for Phytochrome in Etiolated and Green Plants Deduced from Characterization of Arabidopsis thaliana Mutants. The Plant Cell, 1, 867-880. http://dx.doi.org/10.1105/tpc.1.9.867

[50] Pogson, B.J., Niyogi, K.K., Björkman, O. and Della Penna, D. (1998) Altered Xanthophyll Compositions Adversely Affect Chlorophyll Accumulation and Nonphotochemical Quenching in Arabidopsis Mutants. Proceedings of the National Academy of Science of the United States of America, 95, 13324-13329. http://dx.doi.org/10.1073/pnas.95.22.13324

[51] Qin, J.G., Gu, H.Y., Ma, L.G., Peng, Y.B., Deng, X.W., Chen, Z.L. and Qu, L.-J. (2007) Disruption of Phytoene Desaturase Gene Results in Albino and Dwarf Phenotypes in Arabidopsis by Impairing Chlorophyll, Carotenoid, and Gibberellins Biosynthesis. Cell Research, 17, 471-482. http://dx.doi.org/10.1038/cr.2007.40

[52] Carol, P., Stevenson, D., Bisanz, C., Breitenbach, J., Sandmann, G., Mache, R., Coupland, G. and Kuntz, M. (1999) Mutations in the Arabidopsis Gene IMMUTANS Cause a Variegated Phenotype by Inactivating a Chloroplast Terminal Oxidase Associated with Phytoene Desaturation. The Plant Cell, 11, 57-68. http://dx.doi.org/10.1105/tpc.11.1.57

[53] Gabara B. and Kubicka, H. (2000) Comparison of Lethal and Semilethal Chlorophyll Mutants Characterized by Different Expression of Genes Responsible for Colour of Leaves in Winter Rye (Seca/ecereale L.). Caryologia, 53, 227234. http://dx.doi.org/10.1080/00087114.2000.10589200

[54] Zhang, H., Li, J., Yoo, J.H., Yoo, S.C., Cho, S.H., Koh, H.J., Seo, H.S. and Paek, N.C. (2006) Rice Chlorina-1 and Chlorina-9 Encode ChlD and ChlI Subunits of Mg-Chelatase, a Key Enzyme for Chlorophyll Synthesis and Chloroplast Development. Plant Molecular Biology, 62, 325-337. http://dx.doi.org/10.1007/s11103-006-9024-z

[55] Keddie, J.S., Carroll, B., Jones, J.D.G. and Gruissem, W. (1996) The DCL Gene of Tomato Is Required for Chloroplast Development and Palisade Cell Morphogenesis in Leaves. The European Molecular Biology Organization (EMBO) Journal, 15, 4208-4217.

[56] Chatterjee, M., Sparvoli, S., Edmunds, C., Garosi, P., Findlay, K. and Martin, C. (1996) DAG, a Gene Required for Chloroplast Differentiation and Palisade Development in Antirrhinum majus. The European Molecular Biology Organization (EMBO) Journal, 15, 4194-4207.

[57] Mandel, M.A., Feldman, K.A., Herrera-Estrella, L., Rocha-Sosa, M. and León, P. (1996) CLA1, a Novel Gene Required for Chloroplast Development, Is Highly Conserved in Evolution. The Plant Journal, 9, 649-658. http://dx.doi.org/10.1046/j.1365-313X.1996.9050649.x

[58] Solymosi, K. and Schoefs, B. (2010) Etioplast and Etio-Chloroplast Formation under Natural Conditions: The Dark Side of Chlorophyll Biosynthesis in Angiosperms. Photosynthesis Research, 105, 143-66. http://dx.doi.org/10.1007/s11120-010-9568-2

[59] Gutiérrez-Nava, M., Gillmor, C.S., Jiménez, L.F., Guevara-García, A. and León, P. (2004) Chloroplast Biogenesis Genes Act Cell and Noncell Autonomously in Early Chloroplast Development. Plant Physiology, 135, 471-482. http://dx.doi.org/10.1104/pp.103.036996

[60] Pogson, B.J. and Albrecht, V. (2011) Genetic Dissection of Chloroplast Biogenesis and Development: On Overview. Plant Physiology, 155, 1545-1551. http://dx.doi.org/10.1104/pp.110.170365

[61] Hills, A.C., Khan, S. and Lopez-Juez, E. (2015) Chloroplast Biogenesis-Associated Nuclear Genes: Control by Plastid Signals Evolved Prior to Their Regulation as Part of Photomorphogenesis. Frontiers in Plant Science, 6, 1078. http://dx.doi.org/10.3389/fpls.2015.01078

[62] Kroll, D., Meierhoff, K., Bechtold, N., Kinoshita, M., Westphal, S., Vothknecht, U.C., Soll, J. and Westhoff, P. (2001) VIPP1, a Nuclear Gene of Arabidopsis thaliana Essential for Thylakoid Membrane Formation. Proceedings of the National Academy of Science of the United States of America, 98, 4238-4242. http://dx.doi.org/10.1073/pnas.061500998

[63] Kobayashi, K., Kondo, M., Fukuda, H., Nishimura, M. and Ohta, H. (2007) Galactolipid Synthesis in Chloroplast Inner Envelope Is Essential for Proper Thylakoid Biogenesis, Photosynthesis, and Embryogenesis. Proceedings of the Na- 
tional Academy of Science of the United States of America, 104, 17216-17221 http://dx.doi.org/10.1073/pnas.0704680104

[64] Wang, Q., Sullivan, R.W., Kight, A., Henry, R.L., Huang, J., Jones, A.M. and Koryh, K. (2004) Deletion of the Chloroplast-localized Thylakoid Formation1 Gene Product in Arabidopsis Leads to Deficient Thylakoid Formation in Variegated Leaves. Plant Physiology, 136, 3594-3604. http://dx.doi.org/10.1104/pp.104.049841

[65] Bachmann, M.D., Robertson, D.S., Bowen C.C. and Anderson, I.C. (1967) Chloroplast Development in Pigment Deficient Mutant of Maize: I. Structural Anomalies in Plastids of Allelic Mutants at the $w_{3}$ Locus. Journal of Ultrastructure Research, 21, 41-60. http://dx.doi.org/10.1016/S0022-5320(67)80005-4

[66] Burns, E.R., Buchanan, G.A. and Carter, M.C. (1971) Inhibition of Carotenoid Synthesis as a Mechanism of Action of Amitrole, Dichlormate, and Pyriclor. Plant Physiology, 47, 144-148. http://dx.doi.org/10.1104/pp.47.1.144

[67] García-Valenzuela, X., García-Moya, E., Rascón-Cruz, Q., Herrera-Estrella, L. and Aguado-Santacruz, G.A. (2005) Chlorophyll Accumulation is Enhanced by Osmotic Stress in Graminaceous Chlorophyllic Cells. Journal of Plant Physiology, 162, 650-661. http://dx.doi.org/10.1016/j.jplph.2004.09.015 